\title{
Evaluating Stapler Based Ileal Neobladders in Terms of Function and Patient Satisfaction, An NCI Experience
}

\author{
SHARIF A. ABDEL-KARIM, M.Sc.*; ABDALLA M. ELAZAB, M.Sc.*; EMAN EL-DESOUKY, Ph.D.**; \\ EHAB S. HUSSIEN, M.D.*; ABDEL-MAKSOUD MOHAMMAD, M.D.* and ISMAIL A. MOURAD, M.D.*
}

The Departments of Surgery* and Biostatistics**, the National Cancer Institute, Cairo University

\begin{abstract}
Aim of the Study: Description of the results of using the stapler based ileal neobladders for reconstruction after radical cystectomy in a subset of patients in the National Cancer Institute of Cairo University in Egypt in terms of functional outcome and patient satisfaction.

Patients and Methods: In 2014, A prospective interventional study was carried out in the National Cancer Institute involving 29 patients with bladder cancer who met the criteria for neobladder reconstruction after radical cystectomy for whom a modified Y shaped ileal neobladder was created after tumor exanteration aiming at exploring functional outcomes and patient satisfaction rates for a period of one year in such a group of patients compared to other published reconstructive options.
\end{abstract}

Results: The mean value of maximum neobladder capacity was $445 \mathrm{ml}$, the mean pressure at maximum neobladder capacity was $22 \mathrm{~cm} \mathrm{H} 2 \mathrm{O}$ and the mean post-voiding urine residual was about $20 \mathrm{ml}$. By 6 months' post operatively, about $85 \%$ of the cases expressed having a good quality of life evidenced by satisfaction about their body image, daily maintenance and general satisfaction.

Conclusion: Orthotopic neobladder reconstruction using the Y (Fontana) ileal neobladder can be considered as a simple and practical solution for neobladder reconstruction after radical cystectomy in Egyptian bladder cancer patients.

Key Words: Y pouch-Bladder cancer-Clavien Dindo classification.

\section{Introduction}

CONTINUOUS trials for an ideal urinary reservoir following radical cystectomy for muscle invasive bladder malignancies is the best evidence that an (ideal) orthotopic neo-bladder has not been achieved. Several reconstructive options were proposed, and with these trials new concerns and drawbacks had to be addressed.

Correspondence to: Dr. Sharif A. Abdel-Karim,

The Department of Surgery, the National Cancer Institute, Cairo University
Fontana et al. [1] published their preliminary results in the so called (Y) ileal pouch for orthotopic continent bladder reconstruction in 2001, then published a more detailed study on the technical aspects in 2004 [2]. They stated that it is a simple, safe, considerably fast, and mostly reliable method with promising results.

In this study, we introduced this relatively new technique in the National Cancer Institute in Cairo University aiming at exploring the functional and satisfaction results among the Egyptian population.

\section{Patients and Methods}

Between August 2014 and January 2016, 29 cases of bladder cancer were recruited and met the inclusion criteria for orthotopic bladder reconstruction following radical cystectomy. The procedure and possible complications were explained in detail for every patient and an informed consent, that was approved by the institutional review board (IRB), signed by every patient and co-signed by the performing surgeon.

Data management and statistical analysis were performed using the Statistical Package for Social Sciences (SPSS) version 21.

Numerical data were summarized using means and standard deviations. Categorical data were summarized as percentages. Comparisons between the 2 groups regarding normally distributed numeric variables were done using the $t$-test. For categorical variables, differences were analyzed with chi square test and Fisher's exact test when appropriate.

All $p$-values are two-sided. $p$-values $<0.05$ were considered significant.

Inclusion criteria were non-metastatic disease, negative biopsies from the prostatic urethra in 
males and bladder neck in females (by cystoscopy or frozen section), adequate renal function (defined as creatinine $<150 \mathrm{umol} / \mathrm{L}$ ), no active inflammatory bowel disease and compliance to routine followup.

Exclusion criteria were unhealthy bowel (including inflammatory bowel disease or any other pathology), unmotivated patient, prior pelvic radiation (impaired healing) and performance status [defined by American Society of Anesthesiologists (ASA) grade >2].

Patients were informed of the procedure in details, the follow-up regimen and the investigations. An informed consent will be signed by the patient and co-signed by the treating physician.

Preoperative preparation entailed pre-operative cystoscopy to assess the tumor site and invasiveness and for obtaining a biopsy and distance from bladder neck, complete blood picture, hepatic and renal function profiles and coagulation profiles for performance status assessment, plain chest radiography, abdominal and pelvic CT scan, bowel preparation and electrolyte check the night before the operation.

The procedure entails the following: [1]

- Radical Cystectomy with urethral sphincter sparing.

- Taking $40 \mathrm{cms}$ of the distal ileum after sparing $20 \mathrm{cms}$ from the ileo-caecal junction.

- Separating this loop of ileum with its mesentery and performing an ileo-ileal anastomosis.

- Anastomosis using linear staplers in both procedures (ileal loop separation and ileo-ileal anastomosis.

- Folding the ileal loop in a U shape to reach the urethra at the curved tip and both ureters at each limb

- A small puncture at the curved tip is performed and then $15 \mathrm{cms}$ are de-tubularized by a linear stapler leaving $5 \mathrm{cms}$ at the end of each limb with closed ends.

- The ureters are then anastomosed after spatulation [3] retroperitoneally either end to end or end to side to the ipsilateral $Y$ pouch arm after insertion of a ureteric stent of French size 4.5 with the end extruded in the three-way catheter from the urethral opening.

- Urethral anastomosis was performed over a threeway silicone catheter.

- Water tightness is checked intraoperatively using colored water-soluble agent.
- Ascending cystography was performed 2 weeks after discharge and the stents will be removed 2 weeks after discharge by Cystoscopy.

Maximum neobladder capacity, pressure at maximum neobladder capacity, post voiding residual urine and patient satisfaction were all assessed in our study for a period of one year prospectively.

Urodynamics were done in the first settlement section of the national cancer institute at 6 months postoperative using the UDS-600 software and a standard water-filled external transducer-type device. Maximal neobladder capacity was defined by the patient having his first urge, abdominal discomfort or pain or the point at which leak begins. Pressure at maximal neobladder capacity was recorded in $\mathrm{cm} \mathrm{H} 2 \mathrm{O}$. Post voiding residual urine was calculated by allowing the patient to evacuate upon a graduated collector then subtracting the output from the input provided by the device.

Quality of life (including body image, daily maintenance and satisfaction in general) at 1,3 and 6 months duration post-operative, it was assessed through a subjective questionnaire regarding the aforementioned three criteria with scoring of (1Poor. 2- Average. 3- Good and 4- Excellent).

\section{Results}

As for urodynamic studies of the neobladder, the mean value of maximum neobladder capacity was $445 \mathrm{ml}$ with a standard deviation of 73 and a median of $433 \mathrm{ml}$. The mean pressure at maximum neobladder capacity was $22 \mathrm{~cm} \mathrm{H} 2 \mathrm{O}$ with a standard deviation of 4 . And the mean post-voiding urine residual was about $20 \mathrm{ml}$.

Table (1): Urodynamics and operative time values.

\begin{tabular}{lccccc}
\hline & Mean & SD & Median & $\begin{array}{c}\text { Min- } \\
\text { imum }\end{array}$ & $\begin{array}{c}\text { Max- } \\
\text { imum }\end{array}$ \\
\hline Age (years) & 59 & 8 & 61 & 41 & 74 \\
$\begin{array}{l}\text { Time to create the ne- } \\
\text { obladder (mins.) }\end{array}$ & 34 & 8 & 30 & 25 & 60 \\
$\begin{array}{l}\text { Maximum neobladder } \\
\text { capacity at 6 months } \\
\text { (ml) }\end{array}$ & 445 & 73 & 433 & 320 & 601 \\
$\begin{array}{l}\text { Pressure at maximum } \\
\text { neobladder capacity } \\
\text { (cm H2O) }\end{array}$ & 22 & 4 & 22 & 11 & 29 \\
$\begin{array}{c}\text { Post voiding residual } \\
\text { urine (ml) }\end{array}$ & 19 & 18 & 20 & 0 & 80 \\
$\begin{array}{c}\text { Approximate whole op- } \\
\text { erative time (mins.) }\end{array}$ & 186 & 9 & 180 & 180 & 210 \\
\hline
\end{tabular}


By 6 months' post operatively, about $85 \%$ of the cases expressed having a good quality of life evidenced by satisfaction about their body image, daily maintenance and general satisfaction. Patient satisfaction depends mainly upon expectations preoperatively and the patients' ability to provide an informed consent after thorough discussion of the different treatment options.

Table (2): Quality of life assessment.

\begin{tabular}{llll}
\hline & & No. & $\%$ \\
\hline QOL 1 & Fair & 14 & 48.3 \\
& Good & 12 & 41.4 \\
& Poor & 3 & 10.3 \\
QOL 3 & Fair & 6 & 23.1 \\
& Good & 19 & 73.1 \\
& Poor & 1 & 3.8 \\
QOL6 & Fair & 4 & 15.4 \\
& Good & 22 & 84.6 \\
& Poor & 0 & 0 \\
\hline
\end{tabular}

Of note as well, pouch calculi were reported in only one case (3\%) and it was easily crushed cystoscopically. Renal stones were reported in two cases $(7 \%)$ and were managed by stenting and lithotripsy with no need for further open surgery.

\section{Discussion}

Discussion of different aspects related to the $Y$ pouch ileal neobladder will involve points related to the pouch creation, assessment-related points, points of strength and possible points of weakness in the study.

\section{Length of the ileal segment:}

After sparing $25 \mathrm{~cm}$ from the distal ileum, the most dependent $40 \mathrm{~cm}$ of the ileum that can reach the urethra without tension is thus used, taking smaller length from the ileum decreases the incidence and severity of metabolic acidosis by decreasing the absorptive surface of the ileum [4] This is considered a point of strength against other well Known pouches like Studer $(60-65 \mathrm{~cm})$ or Hautmann $(70 \mathrm{~cm})$.

\section{Vertical de-tubularized non-spherical pouch:}

A low pressure, high volume reservoir is the purpose of de-tubularization and shape modification, the mean maximal neobladder capacity and the mean pressure at maximal neobladder capacity of $445 \mathrm{ml}$ and $22 \mathrm{~cm} \mathrm{H} 2 \mathrm{O}$ respectively shows that a $40 \mathrm{~cm}$ with vertical shape without spherical folding is comparable to other types of orthotopic diversion. Moreover, similar pressures have been reported by Fontana et al., Hassan et al., and Allen et al., with even slightly higher capacity than those reported $[\mathbf{1 , 5 , 6 ]}$. The incidence of creation of a so called (floppy bag) having large volume of postvoiding residual urine can thus be minimized.

\section{The presence of an anti-peristaltic limb:}

As stated by Fontana, the right anti-peristaltic limb of the pouch is too short to cause obstruction, this can be applied to $\mathrm{W}$ shaped pouches as well $[7,8]$. This will be further validated by selective follow up for the right upper tract in the Y pouch patients on longer terms.

The use of direct anastomotic technique for the ureters:

Controversy exist about the importance of an anti-reflux mechanism, [2,6]. The benefits are not easy to define. The need for reflux prevention is not the same as in uretero-sigmoidostomy, conduit or cutaneous continent diversion [4]. Reflux prevention in a neobladder is even less important than in a normal bladder.

The rationale for implanting the ureters in antireflux fashion in to orthotopic bladder substitutes or continent reservoirs is to prevent the upper urinary tract from retrograde, hydrodynamically transmitted pressure peaks as well as from ascending bacteriuria. However, routine anti-reflux ureter implantation into intestinal urinary reservoirs was born in the era before the creation of designated low pressure reservoirs [3]. Glomerular filtration pressure has been calculated to be 25 to $30 \mathrm{~cm}$ water and the amplitude of the peristaltic waves in the ureters is normally less than $10 \mathrm{~cm}$. In view of these values long periods with pressure exceeding about $25 \mathrm{~cm}$ of water in the urinary receptacle in the long term would probably impair renal function by impeding urine flow. Patients with a continent ileal reservoir for urinary diversion use approximately $60 \%$ of maximal volume capacity during the day, that is about 300 to $500 \mathrm{ml}$. At this reservoir volume pressure exceeds zero by more than $25 \mathrm{~cm}$ water only for about 2 minutes per hour. Using non-refluxing techniques, the risk of obstruction is at least twice that after direct anastomosis irrespective of type or bowel segment used. Half of these strictures require secondary procedure [4] Studer and Zingg reported a 3\% obstruction rate for ureteral direct anastomosis compared with a $13 \%$ rate of postoperative strictures when Coffey flap valves were used [9].

\section{Titanium staplers and stone formation:}

In 2004, an Italian group from Piedmont reported an acceptable $6 \%$ rate of stones formation when fifty Y-shaped orthotopic ileal neobladders were 
created in open surgical procedures with nonabsorbable titanium staples in a mean follow-up of 20 months [1]. Our preliminary study reported just 1 patient to have pouch stones $(3.5 \%)$. One of the largest series addressing stapled orthotopic diversions with 20 years follow-up reported the incidence to be $4.5 \%$ [10]. Growing evidence in published studies suggest that titanium staples are corrosive resistant, have low toxicity and excellent tissue and fluid biocompatibility [11,12] .

The benefits of using stapled diversion over the risks of management of stones, if present, should be weighed before the decision to perform the procedure.

These were the issues raised during the emergence of the Y shaped neobladder as an ileal orthotopic bladder substitute, other issues may reveal themselves during longer periods of follow-up.

\section{So, The Y pouch has the advantages of being:}

- Fast: Mean time to creation is 34 minutes without ureteric anastomosis, which usually takes another 20 to 30 minutes which is about two thirds the time reported by the original author (90 minutes) [1].

- Simple: Needs a shorter learning curve than other types of orthotopic reconstruction, though this is the first study in the national cancer institute, it has gained popularity and many surgeons adopted its use for reconstruction.

- Uses small segment of ileum: This is the smallest reported segment of ileum for ileal neobladder reconstruction, according to Muto et al., the $40 \mathrm{~cm}$ pouch is also reported in Camey II, Padua, and the W pouch reported by Sevin in $2004[\mathbf{1 0 , 1 3 , 1 4 ]}$

- Has two limbs reaching both ureters to be anastomosed in place: This has many advantages namely:

a- Avoiding excessive ureteric dissection and devascularization which is the main cause for ureteric stricture $[\mathbf{1 , 7 , 8 ]}$.

b- Better alignment with the upper tract allowing for better endoscopic access for the kidneys and ureters.

c- Avoids ureteric kinking and subsequent risk of stricture when passed under the mesentery of the rectum or sigmoid.

d- If future nephrectomy or nephrouretrectomy is planned, resection with part of the limb or the whole ipsilateral limb can be done with no need to approach the other side.

e- Avoids the side effects of creation of a Wallace-type anastomosis.
- Can be achieved completely intracorporeally, either through laparoscopic or robotic assisted approaches [11]

Yet the study has some points of weakness that should be addressed in future studies involving The Y pouch:

- The number of patients is considered relatively small compared to the flow of bladder cancer patients in the national cancer institute, this can be attributed to several factors among which is the shortage of staplers in different periods, the late stage of bladder cancer patients as NCI is a tertiary referral center and the difficulty to convince patients with the procedure to obtain an informed consent.

- Details about cost effectiveness of using staplers in comparison with the resources used in more prolonged procedures (suture material, anesthetics, hospital stay and others) was not addressed in this study.

- Quality of life assessment was based upon a simple questionnaire and not a standard assessment tool for QOL assessment.

The authors declare no conflict of interest.

\section{References}

1- FONTANA D., BELLINA M., FASOLIS G., et al.: Yneobladder: An easy, fast, and reliable procedure. Urology, 63 (4): 699-703. doi: 10. 101 6/j.urology.2003.11.015, 2004.

2- DINDO D., DEMARTINES N. and CLAVIEN P-A. Classification of Surgical Complications. Ann Surg., 240 (2):205-213. doi:10.1097/01.sla.0000133083. 54934.ae, 2004.

3- PANTUCK A.J., HAN KR., PERROTTI M., WEISS R.E. and CUMMINGS K.B.: Ureteroenteric anastomosis in continent urinary diversion: Long-term results and complications of direct versus nonrefluxing techniques. J. Urol., 163(2):450-455. http://www.ncbi.nlm.nih.gov/ pubmed/10647652, 2000.

4- HAUTMANN R.E.: Urinary Diversion: Ileal Conduit to Neobladder. J. Urol., 169 (3): 834-842. doi: 10. 1097/0 1.ju. 0000029010.97686.eb, 2003.

5- SIM A., TODENHÖFER T., MISCHINGER J., et al.: Y Pouch Neobladder-A Simplified Method of Intracorporeal Neobladder After Robotic Cystectomy. J. Endourol., 29(4):387-389. doi:10.1089/end.2014.0507, 2015.

6- HASSAN A.A., ELGAMAL S.A., SABAA M.A., SALEM K.A. and ELMATEET M.S.: Evaluation of direct versus non-refluxing technique and functional results in orthotopic Y-ileal neobladder after 12 years of follow-up Investigation. Int. J. Urol., 14(4):300-304. doi:10.1111/j.14422042.2006.01716.x, 2007.

7- FONTANA D., BUFFARDI A. and DESTEFANIS P.: [Urinary diversions and bladder replacement surgery: Evolution, current situation and long-term outcomes]. 
Urologia., 79 (Suppl 1): 41-45. doi:10.5301/RU.2012. 9722, 2012.

8- DESTEFANIS P., BOSIO A., CARCHEDI M.T., et al.: 864 Y-neobladder: An update of a multi-institutional retrospective study. Analysis of late complications through Clavien-Dindo classification. Eur. Urol. Suppl., 12 (1): e864-e865. doi:10.1016/S1569-9056(13)61343-3, 2013.

9- STUDER U.E. and ZINGG E.J.: Ileal orthotopic bladder substitutes. What we have learned from 12 years' experience with 200 patients. Urol. Clin. North Am., 24 (4): 781-793. http://www.ncbi.nlm.nih.gov/pubmed/9391531 Accessed July 9, 2017, 1997.

10- MUTO G., COLLURA D., SIMONE G., et al.: Stapled orthotopic ileal neobladder after radical cystectomy for bladder cancer: Functional results and complications over a 20-year period. Eur. J. Surg. Oncol., 42 (3): 412-418. doi:10.1016/j.ejso.2015.11.010, 2016.

11- ABREU S.C., FONSECA G.N., CERQUEIRA J.B.G., NÓBREGA M.S., COSTA M.R. and MACHADO P.C.:
Laparoscopic radical cystectomy with intracorporeally constructed Y-shaped orthotopic ileal neobladder using nonabsorbable titanium staples exclusively. Urology, 66 (3): 657. doi:10.1016/j.urology.2005.03.021, 2005.

12- GRUBB R.L., SUNDARAM C.P., YAN Y., et al.: Use Of Titanium Staples During Upper Tract Laparoscopic Reconstructive Surgery: Initial Experience. J. Urol., 168 (4): 1366-1369. doi:10.1016/S0022-5347(05)64450-3, 2002.

13- FERRIERO M., GUAGLIANONE S., PAPALIA R., MUTO G.L., GALLUCCI M. and SIMONE G.: Risk Assessment of Stone Formation in Stapled Orthotopic Ileal Neobladder. J. Urol., 193 (3): 891-896. doi:10.1016/ j.juro.2014.09.008, 2015.

14- SEVIN G., SOYUPEK S., ARMAGAN A., HOSCAN M.B. and OKSAY T.: Ileal orthotopic neobladder (modified Hautmann) via a shorter detubularized ileal segment: Experience and results. BJU Int., 94 (3): 355-359. doi:10.1111/j.1464-410X.2004.04933.x, 2004.

\section{تقييم المثانة الصناعية المعوية بإستخدام الدباسة الجراحية

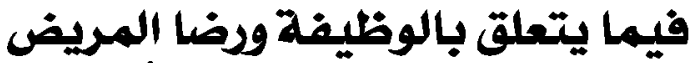 تجرية المعهد القومى للأورام}

المقدمة والآهداف: إن عملية البحث المستمرة عن البديل المثالى المثاثة البولية بعد جراحات الإستئصال الجذرى المثثاثة لهى أكبر دليل

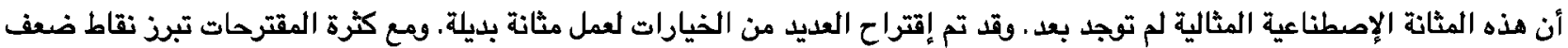
وملاحظات جديدة جديرة بالبحث.

وقد تم في عام عا + ب إجراء دراسة استباقية تداخلية على جY مريض بسرطان المثانة هم من انطبقت عليهم معايير الإختيار، وذلك بإستخدام

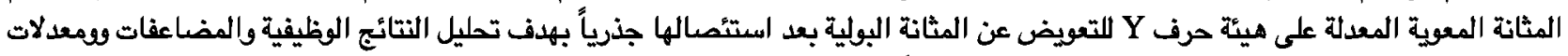

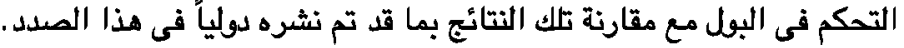

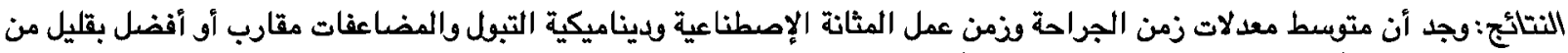

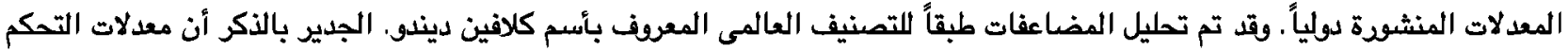

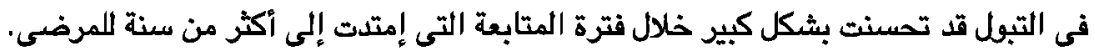

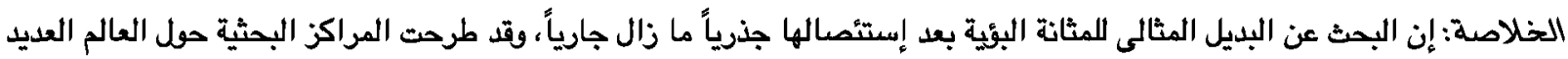

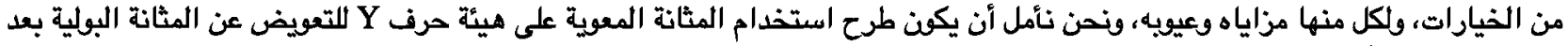

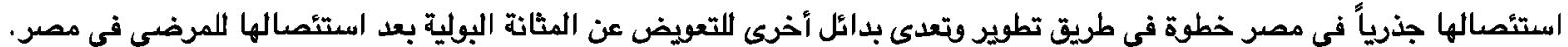

